Pendugaan Umur Simpan Buah Mangga Cengkir Kering - Wulandari, dkk Jurnal Pangan dan Agroindustri Vol.8 No.4: 175-184, Okt 2020

Diterima: 02/10/2019, Direview: 02/12/2019, Diterbitkan: 05/10/2020

\title{
PENDUGAAN UMUR SIMPAN BUAH MANGGA CENGKIR KERING DENGAN METODE AKSELERASI BERDASARKAN PENDEKATAN ARRHENIUS
}

\section{Accelerated Shelf-Life Testing of Dried Mango Cengkir Using Arrhenius Approach}

Endah Wulandari ${ }^{\star}$, Heni Radiani Arifin, Gemilang Lara Utama, Vania Griselda Panjaitan

Fakultas Teknologi Industri Pertanian, Universitas Padjadjaran

Jl. Raya Jatinangor KM 21, Sumedang

*Penulis Korespondensi, Email: endah.wulandari@unpad.ac.id

\begin{abstract}
ABSTRAK
Buah mangga adalah produk yang mudah rusak sehingga perlu dilakukan pengolahan salah satunya menjadi buah kering. Pengeringan osmosis merupakan salah satu metode baru dalam pengeringan buah mangga. Pengeringan osmotik menggunakan larutan gula memungkinkan gula berperan sebagai penarik air sekaligus bahan pengawet alami sehingga dapat memperpanjang umur simpan buah mangga cengkir kering. Perhitungan umur simpan produk buah mangga kering ini dilakukan dengan pendekatan metode Arhhenius dengan pertumbuhan mikroorganisme sebagai titik kritis dengan model regresi linear $y=-56599.4 x+13.67$. Hasil penelitian menunjukkan bahwa umur simpan buah mangga kering adalah 4.47 bulan jika disimpan di suhu $30^{\circ} \mathrm{C}$.
\end{abstract}

Kata kunci: Arrhenius, Buah Kering, Mangga, Osmosis, Umur Simpan

\section{ABSTRACT}

The perishability of mangoes causes it needs to be processed to extend the shelf life. Osmotic drying with soaking fruit in sugar solution is one of the new methods for preserving mangoes. The information about the shelf life of dried cengkir mango is less. The shelf life of dried cengkir mango and the changes in quality during storage show that the growth rate of microorganisms was the critical parameter. The growth rate of microorganism was used as a model by linear regression $y=-56599.4 x+13.67$. The shelf life of dried cengkir mango is 4.47 months at a temperature of $30^{\circ} \mathrm{C}$.

Keywords: Arrhenius, Dry Fruit, Mangoes, Osmotic, Shelf life

\section{PENDAHULUAN}

Mangga (Mangifera indica $L$ ) adalah tanaman hortikultura yang banyak terdapat di Indonesia (Badan Penelitian Tanah, 2008). Proses pengolahan pada buah mangga perlu dilakukan untuk memperpanjang masa simpan, menambah keberagaman pangan, serta menambah nilai ekonomi dari buah mangga. Buah kering adalah salah satu produk olahan dari buah mangga yang cukup populer. Pengolahan buah mangga menjadi produk buah kering dapat memperluas jangkuan pemasaran buah mangga karena umur simpannya yang lebih lama sehingga mampu memberikan nilai tambah (Jannah, 2011).

Proses pengeringan pada pembuatan buah kering dapat dilakukan salah satunya dengan sistem pengeringan osmosis untuk memperbaiki akibat buruk dari proses pengeringan biasa yang menggunakan suhu tinggi. Prinsip dari sistem pengeringan osmosis adalah merendam potongan buah mangga segar di dalam larutan gula dengan konsentrasi tertentu. Perendaman buah mangga di dalam larutan gula selain dilakukan untuk tujuan 
pengeringan secara osmosis dan sebagai bahan pengawet alami pada produk buah mangga cengkir kering (Rozana, Hasbullah, dan Muhandri, 2016). Menurut Buntaran, Astirin, dan Mahajoeno (2011) plasmolisis sel-sel mikroba dihasilkan karena adanya gula yang menarik air sehingga ketersediaan air sebagai syarat pertumbuhan atau aktivitas mikroba menurun. Penggunaan gula sebagai bahan pengawet pada produk buah kering sudah cukup berkembang dalam pengaplikasiannya, namun masih belum diketahui berapa lama gula tersebut masih dapat berperan sebagai bahan pengawet dalam mempertahankan mutu Buah Mangga Cengkir Kering sehingga dapat memperpanjang umur simpannya.

Perhitungan tentang umur simpan perlu dillakukan untuk memastikan produk sampai ditangan konsumen dalam keadaan baik dan aman dikonsumsi. Menurut Asiah, Cempaka, dan David (2018), metode Accerelerated Shelf Life Testing (ASLT) memiliki kelebihan yaitu akurasi dan ketepatan yang cukup besar, waktu pengujian lebih singkat, dan parameter analisis yang lebih banyak. Pendugaan umur simpan Buah Mangga Cengkir Kering dapat menggunakan model Arrhenius dikarenakan Buah Mangga Cengkir Kering sensitif terhadap perubahan suhu penyimpanan. Suhu penyimpanan dapat mempengaruhi gradien kerusakan, seperti memengaruhi kadar air produk, peningkatan jumlah mikroorganisme alami produk, atau juga perubahan organoleptik produk akibat reaksi biokimia.

Tujuan penelitian ini adalah mengetahui umur simpan buah mangga cengkir kering dengan metode pengeringan osmotik terhadap parameter pertumbuhan mikroorganisme dan mutu sensori menggunakan metode ASLT model Arrhenius

\section{BAHAN DAN METODE}

\section{Bahan}

Buah mangga kering varietas cengkir indramayu pada umur kematangan \pm 100 hari., air kemasan, sukrosa komersial. Buah mangga cengkir kering dikemas dengan kemasan komposit (aluminium foil, kertas, dan plastik). Bahan yang digunakan untuk pengujian adalah alkohol $70 \%$, aquades, kemasan aluminium foil, media PCA (Plate Count Agar), dan $\mathrm{NaCl} 0.85 \%$.

\section{Alat}

Inkubator buatan dari bahan stryrofoam dilengkapi dengan lampu neon 5W/12V, thermostat, dan thermometer merupakan alat yang digunakan untuk proses penyimpanan, oven sterilisasi, oven blower, aluminium foil, neraca analitik, refraktometer, laminar air flow cabinet (Esco spec: AHC-4D1) autoclave, inkubator (Memmert Lab spec: IN30), desikator, dan colony counter.

\section{Desain Penelitian}

Analisis kadar air, pertumbuhan mikroorganisme, dan mutu sensori buah mangga cengkir kering dilakukan untuk mendapatkan karakteristik mutu produk awal sebelum penentuan umur simpannya. Penentuan mutu kritis didasarkan pada standar yang telah ditetapkan oleh BSN dalam SNI buah kering (BSN, 1995) dan batasan cemaran mikroorganisme dalam bahan pangan buah kering (BSN, 2009).

\section{Tahapan Penelitian}

\section{Pembuatan dan karakterisasi buah mangga cengkir kering:}

Buah mangga ditimbang sebanyak $2.5 \mathrm{~kg}$ untuk satu perlakuan. Buah mangga dikupas dan dicuci. Pencucian bertujuan untuk menghindari adanya kotoran fisik yang terdapat di kulit buah yang dapat mengontaminasi daging buah. Pengupasan bertujuan untuk memisahkan daging buah dari kulitnya. Buah mangga diiris dengan ketebalan $\pm 0.5 \mathrm{~cm}$ yang memanjang dari pangkal buah hingga ujung. Pengirisan bertujuan untuk mempercepat dan menyeragamkan lama pengeringan dan kadar air akhir pada mangga. Buah mangga yang telah diiris direndam dalam larutan gula. Perendaman dilakukan selama 10 jam dengan banyaknya larutan gula sebesar 0.5 liter (konsentrasi 
$50{ }^{\circ}$ Brix). Buah mangga yang sudah direndam kemudian dibilas dengan air matang dan mengalir. Pembilasan dilakukan agar larutan gula tidak menempel pada mangga yang akan mempengaruhi pada saat pengeringan buah mangga kemudian ditirisakan di atas loyang berlubang berbahan plastik atau stainless. Penirisan bertujuan agar air yang menempel di permukaan buah mangga berkurang dan hilang. Selama proses penirisan juga dilakukan penyusunan buah mangga yang akan dikeringkan. Pengeringan mangga dilakukan menggunakan oven blower dengan suhu $50{ }^{\circ} \mathrm{C}$ sampai kadar air $\pm 15 \%$ (b/b). Buah mangga cengkir kering dikemas menggunakan kemasan komposit (alumunium foil yang dilapisi dengan bahan kertas dan plastik bertujuan untuk menjaga kualitas dan tekstur dari irisan mangga.

\section{Penentuan Umur Simpan dengan Pendekatan Arrhenius:}

Buah mangga cengkir kering disimpan dalam suhu $30{ }^{\circ} \mathrm{C}, 35^{\circ} \mathrm{C}$, dan $40^{\circ} \mathrm{C}$, dilakukan pengamatan setiap 5 hari untuk parameter pertumbuhan mikroorganisme dan setiap 7 hari untuk kadar air dan mutu sensori. Nilai kemiringan (b) dan nilai tetapan (k) untuk menentukan nilai $\mathrm{R}^{2}$ sebagai dasar untuk menentukan orde reaksi (nol dan satu). Penentuan umur simpan buah mangga cengkir kering melalui persamaan:

$$
\text { In } k=\ln k_{0}-(E / R)(1 / T) \text {. }
$$

Metode yang digunakan adalah eksperimental dan dilanjutkan dengan analisis secara deskriptif dengan metode regresi korelasi pada parameter kadar air dan mutu sensori buah mangga kering.

\section{Prosedur Analisis}

Kadar air mangga kering diukur dengan metode gravimetric (AOAC, 2005), Perhitungan total mikroorganisme dihitung dengan metode TPC (Total Plate Count) (Modifikasi BSN, 2006), Uji organoleptik menggunakan mutu hedonik (Setyaningsih, Apriyantono dan Sari, 2010).

\section{HASIL DAN PEMBAHASAN}

\section{Karakteristik Mutu Buah Mangga Cengkir Kering}

Hasil analisis karakteristik mutu awal $\left(Q_{0}\right)$ mangga cengkir indramayu terlihat di Tabel 1.

Tabel 1. Karakteristik Mutu Mangga Cengkir Kering Sebelum Penyimpanan ( $\left.Q_{0}\right)$

\begin{tabular}{clc}
\hline No & \multicolumn{1}{c}{ Parameter } & Nilai \\
\hline 1 & Kadar Air (\%) & 15.59 \\
2 & Pertumbuhan Mikroorganisme (CFU/g) & 25 \\
3 & Warna & 4.40 \\
4 & Aroma & 3.30 \\
5 & Rasa & 4.00 \\
6 & Tekstur & 2.87 \\
\hline
\end{tabular}

Dalam menentukan nilai mutu akhir buah mangga cengkir kering (Qt), digunakan standar berdasarkan Standarisasi Nasional Indonesia (SNI) pada SNI buah mangga kering dan batas cemaran mikroorganisme pada buah kering.

\section{Kadar Air}

Pengukuran kadar air dilakukan sebagai data pendukung dalam penentuan umur simpan Buah Mangga Cengkir Kering. Kadar air Buah Mangga Cengkir Kering pada hari ke0 adalah sebesar $15.58 \%$. Nilai kadar air sudah sesuai dengan standar menurut SNI 01 3710-1995 yang menyatakan bahwa kadar air maksimum pada produk buah kering adalah $31 \%$. Berikut data pengukuran kadar air buah mangga Cengkir Kering selama penyimpanan. 
Tabel 2. Hasil Pengukuran Kadar Air Buah Mangga Kering

\begin{tabular}{cccc}
\hline \multirow{2}{*}{$\begin{array}{c}\text { Waktu } \\
\text { (Minggu) }\end{array}$} & $\begin{array}{c}\text { Kuhu } \\
\mathbf{3 0} \mathbf{~}^{\circ} \mathbf{C}\end{array}$ & $\begin{array}{c}\text { Suhu } \\
\mathbf{3 5}{ }^{\circ} \mathbf{C}\end{array}$ & $\begin{array}{c}\text { Suhu } \\
\mathbf{4 0}\end{array}$ \\
\hline 0 & 15.59 & 15.59 & 15.59 \\
1 & 15.67 & 13.88 & 13.61 \\
2 & 14.95 & 13.11 & 12.65 \\
3 & 14.50 & 12.13 & 11.51 \\
4 & 13.40 & 11.34 & 11.04 \\
\hline
\end{tabular}

Buah Mangga Cengkir Kering yang disimpan pada suhu $40^{\circ} \mathrm{C}$ mengalami penurunan kadar air terbesar, sedangkan laju paling rendah adalah pada sampel yang disimpan pada suhu $30^{\circ} \mathrm{C}$. Menurut Nuraeni (2017), pengurangan kadar air sampel akan sejalan dengan meningkatnya suhu penyimpanan. Suhu yang tinggi dapat menyebabkan pori-pori kemasan memuai sehinggga lebih mudah terjadi migrasi uap air dari bahan (Puspita, Rangga dan Sartika, 2016).

Berdasarkan data nilai koefisien determinasi $\left(R^{2}\right)$ pada Gambar 1 maka diketahui bahwa sebanyak $89 \%, 97 \%$, dan $95 \%$ kadar air sampel mangga pada suhu penyimpanan $30{ }^{\circ} \mathrm{C}, 35^{\circ} \mathrm{C}$, dan $40{ }^{\circ} \mathrm{C}$ dipengaruhi oleh suhu penyimpanan, sedangkan $11 \%$, $3 \%$, dan $5 \%$ sisanya dipengaruhi oleh faktor yang lain seperti kelembaban lingkungan penyimpanan. Berdasarkan nilai koefisien korelasi ( $r$ ), kadar air dan suhu penyimpanan memiliki keeratan hubungan data yang cukup tinggi. Keeratan hubungan ini didukung oleh Arizka dan Daryatmo (2015) yang mengatakan perpindahan uap air disebabkan adanya perbedaan antara \% RH lingkungan dengan $\mathrm{RH}$ produk, yang mana membuat air bebas pada \% $\mathrm{RH}$ yang lebih besar berpindah ke $\mathrm{RH}$ yang lebih kecil.

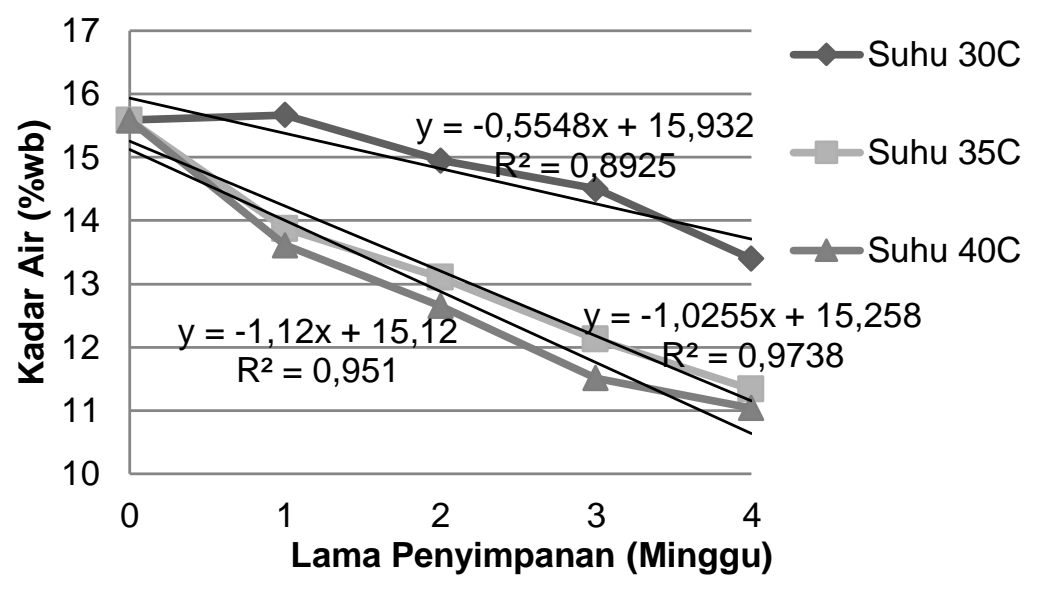

Gambar 1. Perubahan Kadar Air Buah Mangga Cengkir Kering

\section{Pertumbuhan Mikroorganisme}

Mikroorganisme sebagai makhluk hidup memiliki syarat untuk pertumbuhannya, salah satunya yaitu suhu lingkungan. Berikut adalah grafik pertumbuhan mikroorganisme selama 30 hari penyimpanan pada suhu $30^{\circ} \mathrm{C}, 35^{\circ} \mathrm{C}$, dan $40^{\circ} \mathrm{C}$. 


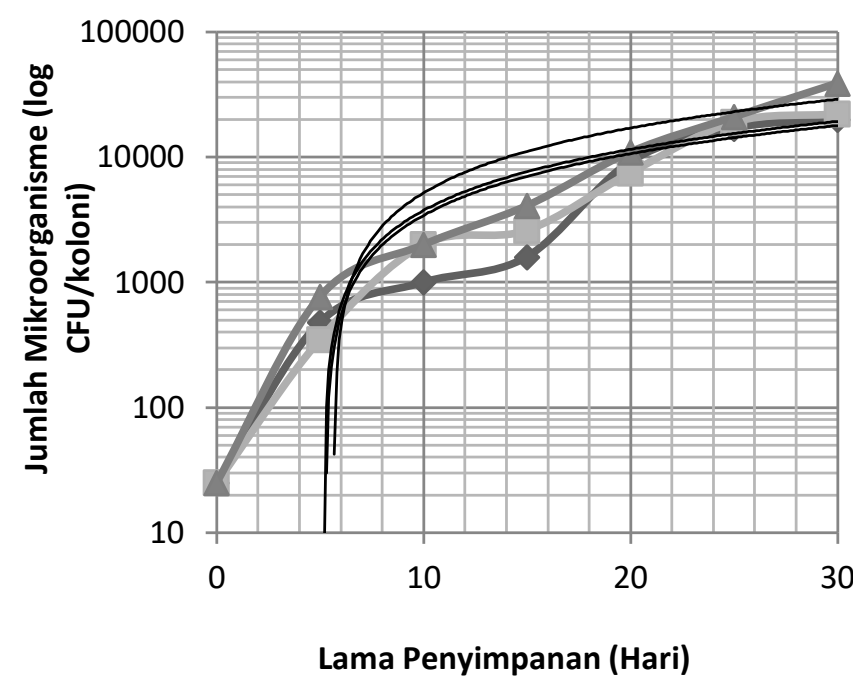

Gambar 2. Pertumbuhan Mikroorganisme Buah Mangga Cengkir Kering Pada

Berbagai Suhu Penyimpanan

Berdasarkan Gambar 2, penyimpanan hingga hari ke-30 di tiga suhu penyimpanan masih menunjukkan jumlah mikroba yang diperbolehkan oleh standar SNI 7388-2009 tentang batas tertinggi mikroorganisme yang terkandung dalam pangan buah kering yaitu ALT (Angka Lempeng Total) yaitu sebanyak maksimum $1 \times 10^{5}$.

\section{Mutu Sensori}

Penilaian sensori dilakukan untuk mengetahui penerimaan konsumen berkaitan dengan penerimaan mutu buah mangga cengkir kering selama 30 hari penyimpanan.

Tabel 3. Penilaian Sensori Buah Mangga Cengkir Kering Selama Penyimpanan

\begin{tabular}{ccccccccccccc}
\hline & \multicolumn{3}{c}{ Warna } & \multicolumn{3}{c}{ Aroma } & \multicolumn{3}{c}{ Rasa } & \multicolumn{3}{c}{ Tekstur } \\
\cline { 2 - 15 } & \multicolumn{3}{c}{ Suhu } & \multicolumn{3}{c}{ Suhu } & \multicolumn{3}{c}{ Suhu } & \multicolumn{3}{c}{ Suhu } \\
\cline { 2 - 14 } & $\mathbf{3 0}$ & $\mathbf{3 5}$ & $\mathbf{4 0}$ & $\mathbf{3 0}$ & $\mathbf{3 5}$ & $\mathbf{4 0}$ & $\mathbf{3 0}$ & $\mathbf{3 5}$ & $\mathbf{4 0}$ & $\mathbf{3 0}$ & $\mathbf{3 5}$ & $\mathbf{4 0}$ \\
\hline 0 & 4.40 & 4.40 & 4.40 & 3.13 & 3.13 & 3.13 & 2.87 & 2.87 & 2.87 & 4.00 & 4.00 & 4.00 \\
7 & 3.30 & 3.67 & 3.23 & 2.87 & 2.93 & 2.27 & 2.37 & 2.53 & 2.30 & 3.00 & 3.37 & 2.93 \\
14 & 3.73 & 3.33 & 3.20 & 3.07 & 2.53 & 2.87 & 2.10 & 2.07 & 2.07 & 3.43 & 2.93 & 2.93 \\
23 & 3.27 & 2.93 & 2.83 & 2.47 & 2.40 & 1.93 & 2.20 & 1.67 & 1.83 & 3.07 & 2.63 & 2.53 \\
30 & 3.13 & 2.67 & 2.30 & 2.40 & 2.00 & 1.67 & 1.97 & 1.33 & 1.33 & 2.63 & 2.17 & 2.00 \\
\hline
\end{tabular}

Berdasarkan hasil pengamatan terjadi penurunan nilai sensori pada parameter warna, aroma, tekstur, dan rasa.

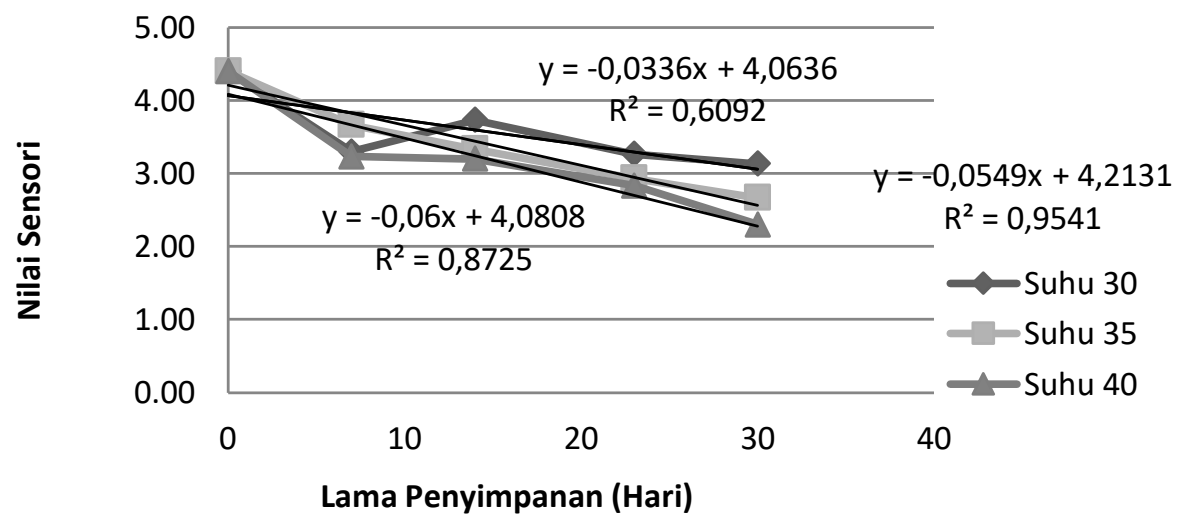

Gambar 3. Penilaian Sensori Warna Buah Mangga Cengkir Kering Selama Penyimpanan 
Pengamatan hari ke-0 menunjukkan buah mangga cengkir kering berwarna kuning. Penurunan mutu warna terjadi selama penyimpanan. Menurut Arsa (2016), proses perubahan warna pada buah mangga cengkir kering terjadi karena proses karamelisasi yang berlangsung apabila sukrosa yang terdapat pada permukaan buah kering mengalami proses pemanasan yang dapat menghasilkan warna kecoklatan.

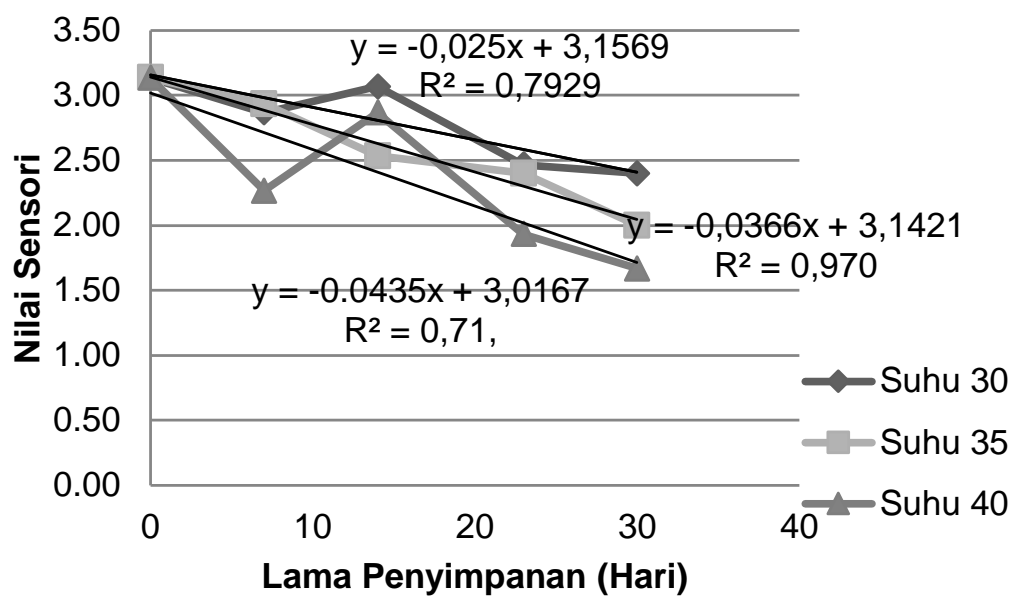

Gambar 4. Penilaian Sensori Aroma Buah Mangga Cengkir Kering Selama Penyimpanan

Pengamatan hari ke-0 menunjukkan buah mangga cengkir kering memiliki aroma khas buah mangga. Penurunan mutu aroma terjadi selama penyimpanan. Penurunan aroma ini dapat disebabkan karena menguapnya senyawa volatil mangga pada kondisi kering (Buntaran et al., 2011). Lingkungan penyimpanan buah mangga cengkir kering pada suhu $40{ }^{\circ} \mathrm{C}$ memiliki \%RH terkecil yang menandakan lingkungan penyimpanannya paling kering, sehingga terjadi penurunan aroma terbesar dibandingkan dengan suhu penyimpanan lainnya.

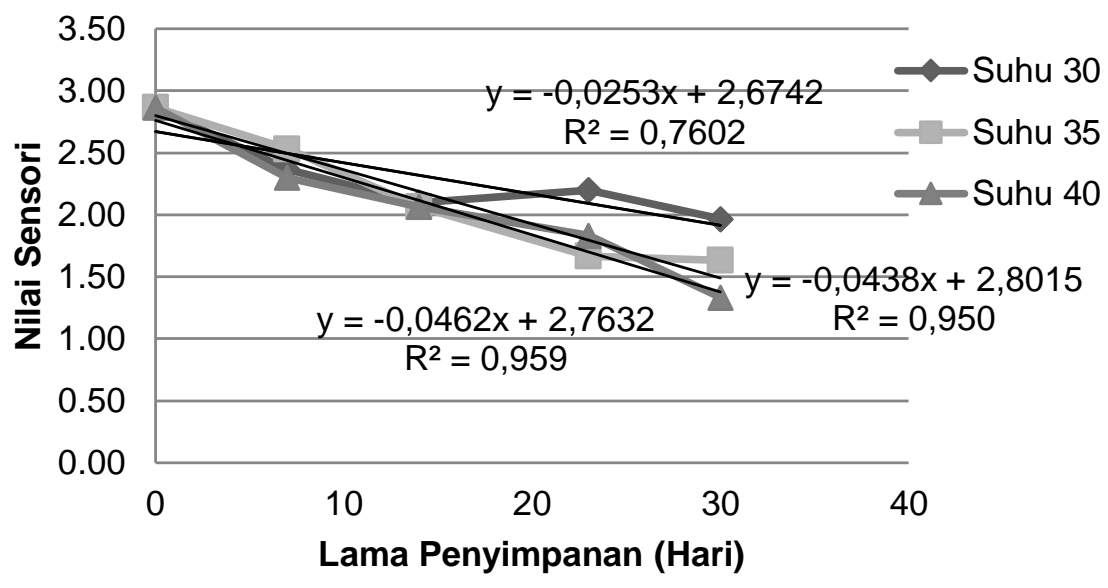

Gambar 5. Penilaian Sensori Tekstur Buah Mangga Cengkir Kering Selama Penyimpanan

Pengamatan hari ke-0 menunjukkan buah mangga cengkir kering memiliki tekstur yang sedikit keras. Penurunan mutu tekstur terjadi selama penyimpanan. Selama penyimpanan, tekstur buah mangga cengkir kering menjadi semakin keras. Hal ini berbanding lurus dengan menurunnya kadar air pada buah mangga cengkir kering. Menurut Budiwaskito (2007), kelembaban yang rendah akan memberikan tekstur yang lebih keras pada sampel buah mangga cengkir kering. 




Gambar 6. Penilaian Sensori Rasa Buah Mangga Cengkir Kering Selama Penyimpanan

Hari pertama pengamatan, produk masih menunjukkan rasa khas buah mangga, namun rasa khas tersebut menurun sejalan dengan lama dan peningkatan suhu penyimpanan. Perubahan tersebut dikarenakan adanya reaksi karamelisasi pada produk sehingga terjadi perubahan rasa maupun warna produk menjadi lebih gelap.

\section{Pendugaan Umur Simpan}

Pemilihan ordo reaksi didasarkan pada nilai $R^{2}$ yang terbesar pada persamaan. Berdasarkan perhitungan dipilih ordo 1 sebagai ordo reaksi. Setelah penentuan ordo reaksi, dilakukan penentuan nilai $k_{t}$ dari masing-masing parameter mutu yang disajikan pada Tabel 6. Pemilihan parameter mutu umur simpan didasarkan pada parameter mutu yang paling sensitif pada suhu yang ditandai dengan nilai $E_{a}$ terendah yaitu terdapat pada parameter pertumbuhan mikroorganisme kemudian dikonversikan menjadi \% Kualitas Indeks.

Tabel 4. Determinasi, tetapan penurunan mutu, energi aktivasi buah mangga cengkir kering

\begin{tabular}{|c|c|c|c|c|c|}
\hline Suhu & Parameter & $\begin{array}{c}\text { Persamaan Regresi } \\
\text { Ordo } 0\end{array}$ & $\begin{array}{c}\text { Persamaan Regresi } \\
\text { Ordo } 1\end{array}$ & $\begin{array}{l}\text { R2 Ordo } \\
0\end{array}$ & $\begin{array}{c}\text { R2 Ordo } \\
1\end{array}$ \\
\hline \multirow{6}{*}{30} & TPC & $y=722.61 x-3795.50$ & $y=0.21 x+4.34$ & 0.8497 & 0.9111 \\
\hline & $\begin{array}{l}\text { \%Quality } \\
\text { Index TPC }\end{array}$ & $y=-0.01 x+1.04$ & $y=-0.01 x+0.04$ & 0.8497 & 0.8428 \\
\hline & Warna & $y=-0.03 x+4.06$ & $y=-0.01 x+1.40$ & 0.6092 & 0.6179 \\
\hline & Aroma & $y=-0.038 x+3.16$ & $y=-0.01 x+0.15$ & 0.7929 & 0.8002 \\
\hline & Tektur & $y=-0.25 x+2.67$ & $y=-0.01 x+0.98$ & 0.7602 & 0.7816 \\
\hline & Rasa & $y=-0.07 x+3.94$ & $y=-0.04 x+3.74$ & 0.9593 & 0.9643 \\
\hline \multirow{6}{*}{35} & TPC & $y=776.61 x-4009.80$ & $y=0.21 x+4.44$ & 0.7989 & 0.9003 \\
\hline & $\begin{array}{l}\text { \%Quality } \\
\text { Index TPC }\end{array}$ & $y=-0.01 x+1.04$ & $y=-0.01 x+0.05$ & 0.7989 & 0.8259 \\
\hline & Warna & $y=-0.06 x+4.21$ & $y=-0.02 x+1.45$ & 0.7989 & 0.8259 \\
\hline & Aroma & $y=-0.04 x+3.14$ & $y=-0.01 x+0.16$ & 0.9541 & 0.9802 \\
\hline & Tektur & $y=-0.04 x+2.80$ & $y=-0.02 x+1.04$ & 0.9706 & 0.9617 \\
\hline & Rasa & $y=-0.07 x+3.86$ & $y=-0.06 x+3.87$ & 0.9503 & 0.9620 \\
\hline \multirow{6}{*}{40} & TPC & $y=1188.50 x-6699$ & $y=0.22 x+4.69$ & 0.7989 & 0.8891 \\
\hline & $\begin{array}{l}\text { \%Quality } \\
\text { Index TPC }\end{array}$ & $y=-0.012 x+1.07$ & $y=-0.01 x+0.09$ & 0.7989 & 0.7555 \\
\hline & Warna & $y=-0.06 x+4.08$ & $y=-0.02 x+1.42$ & 0.7989 & 0.7555 \\
\hline & Aroma & $y=-0.04 x+3.00$ & $y=-0.02 x+1.12$ & 0.8725 & 0.9082 \\
\hline & Tektur & $y=-0.05 x+2.76$ & $y=-0.02 x+1.04$ & 0.7170 & 0.7459 \\
\hline & Rasa & $y=-0.07 x+3.84$ & $y=-0.06 x+3.73$ & 0.9594 & 0.9525 \\
\hline
\end{tabular}


Berdasarkan Tabel 4 dapat diketahui hasil perhitungan menunjukkan nilai $\mathrm{R}^{2}$ dari tiap persamaan sebagian besar parameter menunjukkan reaksi ordo 1 . Nilai $R^{2}$ menunjukkan nilai koefisien determinasi. Nilai tertinggi dapat menjelaskan bahwa reaksi yang terjadi pada penurunan mutu tersebut sesuai dengan reaksi ordo tertentu. Reaksi ordo 1 menunjukkan bahwa perubahan mutu yang terjadi pada buah manga kering menunjukkan laju penurunan secara eksponensial.

Perbedaan ordo reaksi yang terpilih ini dapat terjadi diduga karena penurunan mutu yang terjadi pada produk buah mangga kering yang dipengaruhi oleh suhu penyimpanan dan faktor lain misalnya \%RH. Pengaruh dari faktor lain tersebut dapat memengaruhi laju reaksi penurunan mutu pada buah manga kering sehingga reaksi yang terjadi tidak sesuai dengan grafik linearnya dan menyebabkan ordo reaksi yang terjadi tidak sesuai dengan literatur (Kusnandar, 2006).

Berdasarkan Rumus Persamaan Arrrhenius pada ordo 1: In $\left(k_{t}\right)=\ln \left(k_{0}\right)-$ $\left(E_{a} / R\right)(1 / T)$, dapat diketahui bahwa nilai $E_{a} / R$ merupakan kemiringan dari laju reaksi kerusakan mutu produk Buah Mangga Cengkir Kering. Berikut adalah Tabel data kemiringan $1 / T$ terhadap $\ln (\mathrm{kt})$ dan energi aktivasi pada masing-masing parameter mutu.

Tabel 5. Data Kemiringan Persamaan 1/T dan $\ln \left(\mathrm{k}_{\mathrm{t}}\right)$

\begin{tabular}{lll}
\hline Parameter Mutu & Persamaan Regresi & Energi Aktivasi \\
\hline \%Kualitas Indeks TPC & $\mathrm{y}=-5659.3667+13.7666$ & 11239.53 \\
Warna & $\mathrm{y}=-6919.8384+18.1870$ & 13742.80 \\
Aroma & $\mathrm{y}=-6987.7637+18.0880$ & 13698.96 \\
Tektur & $\mathrm{y}=-7357.2502+19.8095$ & 14611.50 \\
Rasa & $\mathrm{y}=-6234.8402+16.1088$ & 12382.39 \\
\hline
\end{tabular}

Berdasarkan nilai $E_{a}$, parameter yang dijadikan sebagai penentu umur simpan adalah \%Quality Index pertumbuhan mikroorganisme. Parameter \% Quality Index TPC memiliki energi aktivasi terkecil yaitu sebesar $11239.53 \mathrm{kal} / \mathrm{mol}$, sehingga didapatkan grafik nilai $1 / \mathrm{T}$ terhadap $\ln (\mathrm{kt})$ pada parameter \% Quality Index TPC. Parameter yang paling mempengaruhi penurunan mutu buah mangga cengkir kering adalah yang memiliki energi aktivasi terendah karena menunjukkan kontribusi kerusakan produk terbesar (Wasono dan Yuwono, 2014).



Gambar 7. Grafik Regresi 1/T Terhadap $\ln \left(\mathrm{k}_{\mathrm{t}}\right)$

Berdasarkan Gambar 7 didapatkan bahwa nilai $R^{2}$ dari grafik antara 1/T terhadap $\ln \left(\mathrm{k}_{\mathrm{t}}\right)$ adalah 0.8468 , atau sebesar $84.68 \%$ data dalam grafik tersebut berhubungan, namun ada juga faktor lain yang ternyata mempengaruhi data.

Nilai $Q_{0}$ merupakan nilai \% indeks kualitas pada pengamatan hari ke-0. Nilai Qt merupakan \% indeks kualitas dari jumlah total mikroorganisme kritis yang diperbolehkan 
sesuai SNI 2733:2009, yaitu maksimal nilai ALT sebanyak $10^{5} \mathrm{CFU} / \mathrm{g}$. Nilai $\mathrm{k}_{\mathrm{t}}$ diperoleh berdasarkan suhu yang digunakan sebagai suhu penyimpanan, misal untuk umur simpan pada suhu $30^{\circ} \mathrm{C}$ nilai $\mathrm{k}_{\mathrm{t}}$ yang dipakai adalah 0.0074 . Perhitungan umur simpan pada suhu selain suhu penyimpanan pada saat pengujian juga dapat dilakukan dengan menstubtitusikan nilai $1 /$ Treferensi ke dalam persamaan Arrhenius sehingga akan didapatkan nilai $\mathrm{k}$ atau Ink sesuai dengan suhu yang diinginkan. Berikut hasil perhitungan umur simpan buah mangga cengkir kering.

Tabel 6. Hasil Perhitungan Umur Simpan Produk Buah Mangga Cengkir Kering Berdasarkan Ordo Terpilih Pada Berbagai Suhu Penyimpanan

\begin{tabular}{cccccc}
\hline Suhu $\left({ }^{\circ} \mathbf{C}\right)$ & $\mathbf{Q}_{\mathbf{0}}$ & $\mathbf{Q}_{\mathbf{t}}$ & $\mathbf{k}_{\mathbf{t}}$ & Umur Simpan (hari) & Umur Simpan (bulan) \\
\hline 30 & & & 0.01 & 134.30 & 4.48 \\
35 & 0.98 & 0 & 0.01 & 99.20 & 3.31 \\
45 & & & 0.01 & 73.99 & 2.47 \\
\hline
\end{tabular}

Berdasarkan data pada Tabel 6, diketahui bahwa seiring meningkatnya suhu, umur simpan dari buah mangga cengkir kering semakin cepat. Hal ini berlawanan dengan data pada kadar air yang menunjukkan bahwa pada suhu penyimpanan $40^{\circ} \mathrm{C}$ didapatkan hasil kadar air yang semakin menurun seiring penyimpanan. Rendahnya kadar air bebas menunjukkan semakin sulitnya untuk mikroorganisme tumbuh. Data pada grafik pertumbuhan juga menunjukkan bahwa pada suhu $40^{\circ} \mathrm{C}$ peningkatan jumlah mikroorganisme paling tinggi dari dua suhu penyimpanan yang lainnya. Oleh karena itu, asumsi yang dapat digunakan adalah pada kondisi dimana kadar air buah mangga cengkir kering $\pm 11 \%$, mikroorganisme yang terdapat pada produk masih dapat tumbuh. Hal ini dapat terjadi dikarenakan pada buah mangga cengkir kering masih terdapat nutrisi yang cukup selain air untuk metabolisme mikroorganisme tersebut.

\section{SIMPULAN}

Simpulan yang dapat ditarik dari penelitian adalah produk buah mangga cengkir kering dalam kemasan komposit (aluminium foil, kertas, dan plastik) memiliki nilai $E_{a}$ terendah di parameter pertumbuhan mikroorganisme untuk menghitung umur simpan dengan persamaan Arrhenius $y=-5659,4 x+13.767$. Hasil perhitungan umur simpan buah mangga cengkir kering pada penyimpanan suhu $30^{\circ} \mathrm{C}$ adalah 4.47 bulan dan akan menurun seiring dengan meningkatnya suhu. Suhu penyimpanan berpengaruh terhadap kadar air, penilaian sensori, dan pertumbuhan mikroorganisme pada buah mangga cengkir kering

\section{UCAPAN TERIMA KASIH}

Kami mengucapkan terimakasih kepada Rektor Universitas Padjajaran dan Direktorat Riset dan Pengabdian Masyarakat atas biaya penelitian kami di skema Hibah Penelitian Unpad pada tahun 2019

\section{DAFTAR PUSTAKA}

AOAC. (2005). Official Methods of Analysis (18th Editi; W. liam Horwitz, ed.). Maryland: AOAC International.

Arsa, M. (2016). Proses Pencoklatan (Browning Process) Pada Bahan Pangan Oleh Proses Pencoklatan (Browning Process). Denpasar: Fakultas Matematika dan IImu Pengetahuan Alam. Universitas Udayana.

Asiah, N., Cempaka, L., \& David, W. (2018). Pendugaan Umur Simpan Produk Pangan. Jakarta Selatan: Penerbitan Universitas Bakrie.

Arizka, A., \& Daryatmo, J. (2015). Perubahan Kelembaban dan Kadar Air Teh Selama Penyimpanan pada Suhu dan Kemasan yang Berbeda. Jurnal Aplikasi Teknologi 
Pangan, 4(4). https://doi.org/10.17728/jatp.v4i4.6

BSN. Buah Kering. , Pub. L. No. SNI 01-3710-1995 (1995).

BSN. Cara uji mikrobiologi-Bagian 3: Penentuan angka lempeng total (ALT) pada produk perikanan. , Pub. L. No. SNI 01-2332.3-2006 (2006).

BSN. Batas Maksimum Cemaran Mikroba dalam Pangan. , Pub. L. No. SNI 7388:2009 (2009).

Budiwaskito, M. (2007). Pengaruh Tingkat Kematangan Buah Mangga, Perlakuan Perendaman, dan Suhu Penggorengan Vakum Terhadap Karakteristik Fisiokimiawi dan Sensori Keripik Mangga (Mangifera indica L.). Semarang.

Buntaran, W., Astirin, O. P., \& Mahajoeno, E. (2011). Pengaruhh Konsentrasi Larutan Gula terhadap Karakteristik Manisan Kering Tomat (Lycopersicum esculentum). Bioteknologi, 8(1), 1-9.

Jannah, M. (2011). Pengeringan Osmotik pada Irisan Buah Mangga Arumanis (Mangifera indica L.) dengan Pelapisan Kitosan. Bogor.

Kusnandar, F. (2006). Modul Pelatihan Pendugaan dan Pengendalian Masa Kadaluarsa Bahan dan Produk Pangan. Bogor: Institut Pertanian Bogor.

Nuraeni, L. (2017). Pengaruh Suhu Dan Lama Pengeringan Terhadap Karakteristik Tepung Terubuk (Saccharum Edule Hasskarl). Retrieved from http://repository.unpas.ac.id/id/eprint/31012\%0A

Puspita, C. R., Rangga, A., \& Sartika, D. (2016). Kajian Lama Simpan Keripik Pisang Kepok Putih (Musa Acuminate Sp.) Berdasarkan Tingkat Aroma, Rasa Dan Kerenyahan Organoleptik Dalam Berbagai Jenis Kemasan Dengan Model Pendekatan Arrhenius. Inovasi Pembangunan: Jurnal Kelitbangan, 4(03), 278-292.

Rozana, R., Hasbullah, R., \& Muhandri, T. (2016). Response of Drying Temperature on Drying Rate and Quality of Dried Candied Mango (Mangifera indica L.). Jurnal Keteknikan Pertanian, 04(1), 59-66. https://doi.org/10.19028/jtep.04.1.59-66

Setyaningsih, D., Apriyantono, A., \& Sari, M. P. (2010). Analisis Sensori untuk Industri Pangan dan Agro. Bogor: IPB Press.

Tanah, B. P. (2008). Tanaman Mangga (Mangifera indicaL.). Bogor: Badan Penelitian dan Pengembangan Pertanian.

Wasono, M. S. E., \& Setyo Yuwono, S. (2014). Pendugaan Umur Simpan Tepung Pisang Goreng Menggunakan Metode Accelerated Shelf Life Testing Dengan Pendekatan Arrhenius. Jurnal Pangan Dan Agroindustri, 2(04), 178-187. 